\title{
OS QUE SAEM LOGO POR UM FIM, NUNCA CHEGAM AO RIACHO DO VENTO. ESTUDO DA RECEPÇÃO DE “CARA-DE- BRONZE”, DE GUIMARÃES ROSA
}

\section{OS QUE SAEM LOGO POR UM FIM, NUNCA CHEGAM AO RIACHO DO VENTO AN ANALYSIS OF “CARA-DE-BRONZE” WITHIN THE FRAMEWORK OF THE RECEPTION THEORY}

\author{
Camilla Damian Mizerkowski Crestani"
}

Resumo: “Cara-de-Bonze”, publicado primeiramente como poema em Corpo de Baile e posteriormente como conto na coletânea No Urubuquaquá, No Pinhém, foi na data da publicação e ainda hoje é motivo de discussões de cunho genérico, além de suscitar manifestações interpretativas das mais diversas por conta de sua estrutura narrativa formada por partes líricas, em prosa, notas de rodapé, citações e roteiro cinematográfico. Por meio da análise de seis diferentes leitores, este artigo discute as possibilidades de leitura às quais o texto se abre, e se estas podem ser feitas à guisa de puro entretenimento ou se são possíveis somente por meio da análise de seus elementos narrativos, dada sua estrutura polimórfica. Deste modo, o artigo verifica a dificuldade e até mesmo a impossibilidade da leitura gastronômica do conto, e a amálgama de interpretações possíveis, conforme o experimentalismo no uso da multiformidade de discursos.

PALAVRAS-CHAVE: leitura, recepção, compreensão, experimentalismo.

Aвstract: "Cara-de-Bonze", first published as a poem in Corpo de Baile and later as a short story in No Urubuquaquá, No Pinhém, has been an issue of disagreement concerning its literary classification since its publication. Besides, it has arisen several discussions regarding interpretation, for it is built from several genres, for instance: a movie script, quotations and footnotes, prose and lyric devices. Considering six empiric reading approaches, this article shows different interpreting possibilities and whether they may be possible only for entertainment or if the narrative elements

\footnotetext{
"Doutoranda em Letras - Estudos Literários pela Universidade Federal do Paraná. E-mail: camillamcrestani@gmail.com ${ }^{1}$ Trecho de "Cara-de-Bronze" (ROSA, 1976, p. 96)
} 
might also be considered, due to its broken structure. The article also verifies the difficulties and even the impossibilities of ordinary readings, and the ones that come into existence regarding the several literary forms present in the short story.

KEYWORDs: reading, reception, comprehension, experimentalism.

\section{INTRODUÇ̃̃o}

"Cara-de-Bronze", um dos contos mais experimentalistas de João Guimarães Rosa, paira em meio a uma névoa interpretativa, mesmo depois de cinquenta anos de publicação. Classificado como poema nas duas primeiras edições de Corpo de Baile, recebe na terceira edição ${ }^{2}$ a classificação de conto, que vigora até os tempos hodiernos, tendo sido também chamado de novela e até mesmo peça teatral, assunto mal resolvido pela crítica especializada. Não somente a sua classificação genérica, como também sua interpretação provoca uma querela de argumentações. Culpada por esta variedade de possibilidades de nomenclatura, sua estrutura polimórfica - com elementos líricos, teatrais e cinematográficos, mesclados a notas de rodapé e citações - suscita diversas leituras que abrangem desde uma abordagem metaficcional, a abordagens metafísicas, psicanalíticas, mitopoéticas entre outras, que arriscam um significado que dê sentido à soma de sua forma e dos temas recorrentes em toda a obra de Rosa.

São várias as forças que conspiram para a criação do desafio que o texto figu-

\footnotetext{
${ }^{2}$ Primeiramente publicado na Coleção Sagarana em 1956, no volume de subtítulo Corpo de Baile. Aparece pela primeira vez ao lado de "O recado do morro" e "Lélio e Lina" formando o volume No Urubuquaquá, No Pinhém em 1976.
}

ra para os leitores. A principal é a estrutura do texto, que se soma aos temas abordados recorrentemente em Rosa - a viagem, a travessia, o maravilhoso - para a decifração do enigma final, ou seja, o tema último do conto. Podemos também citar, dentro da estrutura, as referências a Goethe, Dante, e a mitos regionais dos sertões de Minas Gerais, bem como o fato de o leitor ver-se compelido a travar uma brincadeira de esconde-esconde com as várias instâncias narrativas, que ora desanuviam alguns fatos da trama, ora encobrem outros, engajando-se em um jogo que perdura até mesmo depois de encerrada a leitura, uma vez que a trama não se resolve explicitamente ao final de suas linhas. Como abordar a compreensão de um texto que fala de si mesmo, como uma narrativa mise en abymes, para decifrar seu tema final, que é o seu grande enigma? A partir da discussão de Wolfgang Iser (199) sobre a estética da recepção e de Umberto Eco (1989) sobre o prazer, o sucesso, o consumo e a abertura de obras literárias, verificamos como se configurou a leitura e interpretação do conto quando de seu lançamento, e alguns exemplos de como é lido contemporaneamente, a partir de seis leitores que nos servem de base para estudo. ${ }^{4}$

\footnotetext{
${ }^{3}$ Empregando a expressão de André GIDE.

${ }^{4}$ São seis os leitores que selecionei para a composição
} 
Segundo uma perspectiva que não busca elucidar ou comprovar o sentido cósmico do texto, mas vê-lo à luz de uma teoria da recepção a partir de experiências reais, partimos de duas premissas básicas para este estudo. A primeira afirma que o texto é um evento, e ocorre quando é processado pelo leitor, no ato da leitura (ISER, 1999, p. 26). A segunda questiona a moldura imposta pelos seus elementos formais, induzindo - parcial ou totalmente - o leitor a certa interpretação, considerando seu repertório. A discussão aborda as dificuldades de interpretação e, a partir delas, a possibilidade de a obra atingir o público geral ou de configurar-se como um conto direcionado exclusivamente a um grupo especializado, se consideradas as dificuldades que o fruidor enfrenta, tanto em relação às quebras narrativas, que impedem a leitura linear da trama, quanto às inúmeras referências a grandes clássicos universais e a elementos da cultura local apresentada pelo texto.

\section{As LEITURAS E SUAS CONQUISTAS}

Segundo Iser (1999, p. 21) "uma teoria do efeito estético se funda no texto, ao passo que uma estética da recepção é derivada

desse artigo. Dois colegas voluntários, uma da área de saúde e outro da área de Letras, fizeram uma leitura rápida do conto e me passaram por escrito suas impressões e interpretação do texto. Os outros quatro são estudiosos da obra de Guimarães, e cada um publicou um artigo sobre o conto "Cara-de-Bronze" a partir de perspectivas bastante diferentes. São eles: Leitora 1 - Mariana Mizerkowski, 26 anos, estudante de medicina; Leitor 2 - um mestrando em Letras/Estudos Literários pela Universidade Federal do Paraná, que pediu para permanecer anônimo, Leitor 3 - Benedito Nunes (1962, 1967), Leitor 4 - Rui Mourão (1994), Leitora 5 - Cleuza R. P. Passos (2001) e Leitor 6 - Heitor Martins (1983). de uma história de juízos de leitores reais". Desse modo, os efeitos historicamente datados que este conto específico de Rosa provocou se constituem nos juízos de valores que variados leitores - separados geográfica e cronologicamente - fizeram do texto, determinando a direção da nossa análise do leitor para o texto, e não vice-versa. Analisando seis leituras diferentes verificaremos algumas possibilidades de interpretação que um texto tão rico em referências extratextuais e discursivo suscita. Na mesma passagem Iser afirma que a estética da recepção "lida com leitores reais, concretos, por assim dizer, leitores cujas reações testemunham experiências historicamente condicionadas das obras literárias" e considerando que "um mesmo texto gera interpretações muito diferentes, senão contrárias" (ISER, 1999, p. 22), partiremos de leitores com repertórios diferentes que se voltam ao texto por motivos diversos.

Qual é, então, a dialética entre texto e leitor quando o último se vê perante uma obra que demanda tamanho labor para seguir sua linha narrativa? Qual leitor permitirá que sua imaginação seja ativada para construir o sentido do texto dentro do seu contexto histórico, social e individual, e dentro das suas limitações referenciais e mentais? Dadas as possibilidades de leitura vislumbradas neste estudo, o efeito desejado pelo autor para seu texto paira como uma última questão de difícil resposta que não abordo aqui, por não ser o objeto deste estudo.

Segundo Eco (1989, p.101), um texto pode ser manuseado de maneiras diferentes, 
dependendo da postura do leitor, que tem a possibilidade de se ater ao que é contado ou ao como a narrativa é construída. Um primeiro tipo de leitor - ou aquele em busca de mero entretenimento - irá certamente encontrar diversos problemas na compreensão de "Cara-de-Bronze", uma vez que a interpretação encontra barreiras na construção não linear da narrativa, cuja personagem-título não aparece "fisicamente", senão na fala de outros personagens, sem definição clara. $\mathrm{O}$ segundo personagem a quem recorreríamos é o vaqueiro Grivo, cuja viagem poderia oferecer alguma luz à narrativa. Porém, o seu objetivo é contingente na narrativa, permanecendo obscuro para as outras personagens e para alguns dos leitores que cederam o testemunho de sua experiência para o desenvolvimento desse artigo. Portanto, tanto a história da personagemtítulo - que apesar de comentada por outras personagens e por um narrador onisciente continua inerte - quanto o destino do herói Grivo ficam imersos em densas nuvens, exigindo um trabalho árduo por parte do leitor para estabelecer um significado. Esta aparente carência de sentidos de orientação abre a obra em uma ambiguidade que a própria estrutura da narrativa propõe. Parece uma maneira que o autor encontra encontra para gerar a leitura em certo sentido, ou como Rosa, para abrir esta leitura em diversos sentidos. A variedade de discursos e a ordem em que são apresentados permitem que o leitor percorra vários caminhos que o levem a uma interpretação plausível segundo o próprio texto, mas que se faça em uma relação dialética com a subjetividade do leitor (ECO, 1971, p.47).

Essas questões revelam-se importantes para uma discussão da validade de uma abordagem gastronômica de "Cara-de-Bronze", que supostamente daria conta de resolver os problemas interpretativos relevantes ao enredo (e somente ao enredo) da obra e conferir-lhe um sentido, comprovado dentro das limitações do texto. Se esta hipótese for comprovada falsa, então esta seria uma obra direcionada puramente a uma fruição estética, caso que excluiria leitores não avisados e despreparados, sem os devidos mecanismos investigativos ativados para resolver as dificuldades que o texto propõe e, sob essa ótica, impõe. Levantamos, desse modo, a hipótese de que o leitor-modelo de "Cara-de-Bronze" é um sujeito passível de definição, uma vez que o estudo de leituras feitas por pessoas reais, ou seja, leitores empíricos, respondem a algumas das indagações já propostas.

Mesmo correndo o risco de afirmar o óbvio, Eco (1989, p. 100) levanta a questão de que, por um lado, há um indiscutível desejo de ser lido por parte de todos os autores, mesmo dos mais experimentalistas. De outro lado, há uma inegável aspiração do prazer na leitura por parte do fruidor. A partir dessa perspectiva, a decifração de enigmas, como o que acontece em romances policiais, faz parte do prazer final da obra, conferindo uma espécie de satisfação do "dever cumprido" no leitor. O repertório deste é claramente provocado pelo texto, cuja elaboração mexe e fala com seu interlocutor, ou seja, o leitor empírico. 
Resolver os problemas da trama torna-se, portanto, parte da leitura. Sob esta ótica, podemos avaliar se unir o prazer do narrado ao prazer estético é possível, ou se

Podemos ainda identificar o agradável com o não-artístico? Podemos ainda identificar o consolador com o que satisfaz o horizonte de expectativas do fruidor e que, portanto, não inova e não provoca? Ou, até mesmo, podemos ainda colocar de um lado o consolador, o não-inovador, o esperado, e do outro o inesperado, o informático, o provocador, o que, em suma, produziria prazer de ordem superior, e não banal? (ECO, 1989, p. 103)

A partir da análise das diferentes leituras sobre o conto, perceberemos se é possível traçar uma linha divisória entre o texto que proporciona prazer estético de ordem superior e o de mero consumo gastronômico, e se as dificuldades que o texto propõe permitem que essa divisão defina tão nitidamente os leitores de níveis diferentes. A leitura de Mariana Mizerkowski (leitora 1) lança alguma luz sobre essa discussão. Em seu depoimento por escrito ela desabafa:

Os neologismos e regionalismos não são fáceis de entender. A conversa entre os vaqueiros é confusa. (E o próprio narrador avisa isso!!!). O livro já estava sublinhado e foi ruim ler assim. A viagem do Grivo nunca é apresentada. E no fim, não sei bem quem era o Cara-de-Bronze.

A partir desse pequeno parágrafo, constatamos que não houve possibilidade desta leitora aproximar-se de uma inter- pretação satisfatória do texto. Ela não pôde compreender a razão de ser dos múltiplos discursos e, desse modo, não entra no jogo proposto pelo autor. Iser (1999, p. 28) afirma que há uma lacuna primeiramente entre texto e leitor, um entre lugar que, se não transposto, provoca a sua aniquilação. Trava-se então uma espécie de negociação entre leitor e texto, o que propicia diversas leituras, não necessariamente excludentes, mas complementares. O que verificamos aqui é a impossibilidade de esta leitora travar um primeiro contato com o texto, pois não reconhece em suas quebras e em sua falta de continuidade o formato de um conto. Há um diálogo tênue entre ela e um narrador, que apenas confirma sua sensação de que a leitura é difícil. Contentando-se com a falta de sentido, confirmada dentro do próprio conto ("A conversa entre os vaqueiros é confusa. (E o próprio narrador avisa isso!!!)”) o abandona, terminando sua leitura como um mero favor à produtora deste artigo. As lacunas e negações internas que mexem com as expectativas do leitor nem chegam a ser percebidas, uma vez que a primeira barreira entre ela e o texto não foi extinta.

Como uma leitora não especializada, Mariana esperava uma narrativa linear e temas tratados explicitamente ao longo do conto. Além do que, ignorou as notas de rodapé, citações e cantigas, não as reconhecendo como partes integrantes do conto, mas sim elementos meramente decorativos, pois notas e citações são comumente encontradas em ensaios e obras científicas, e fornecem informações reais e complementares ao texto principal, 
tradicionalmente não pertencendo a textos ficcionais. A possibilidade de não serem dados extras e sim inerentes à narrativa é desconsiderada, o que agrava ainda mais a incompreensão do conto, e uma segunda leitura é inevitavelmente descartada. A leitura de Mariana parece, enfim, muito rasa em uma primeira análise; mais a fundo percebemos que a falta de compreensão do texto de Rosa se dá por uma soma de seu caráter experimental, tanto no que diz respeito à forma, quanto ao seu tema (a busca das Palavras, a busca do Nome das Coisas $^{5}$ ), e da inexperiência da leitora com textos não lineares.

O leitor que é vítima das estratégias enunciativas, que prefere ser vítima ou que não conhece outra possibilidade de postura diante de um texto não encontra prazer em sua leitura, e deixa de lado "Cara-de-Bronze" antes mesmo de chegado ao fim. Quando o leitor não é capaz de atingir o nível de pensar sobre o texto, de dar-lhe um significado que englobe tanto o enredo quanto a sua forma, ele não identifica aquele amontoado de palavras como um conto, novela, poema ou peça teatral (vemos aí como os problemas de classificação do texto de Rosa tangem um assunto muito mais profundo que o meramente genérico). Mais uma pergunta surge desta pequena análise: a responsabilidade de fazer-se entender é então do texto, ou ele despeja em seu leitor toda a sua incompreensão, e este acaba por sentir-se frustrado, incapaz de decifrar seus códigos?

Percebemos, já nesta primeira leitura exposta, que nem o formato do conto nem o tema atendem às expectativas de uma leitora que busca o prazer da leitura no que é narrado, e costuma ignorar o como. Sendo a tessitura da narrativa parte integrante de seu tema, quando ignorada o texto perde também seu sentido. Outras interpretações de quem é o Cara-de-Bronze, do motivo da viagem de Grivo, da existência da Noiva não expressas explicitamente pelo texto são impossíveis neste nível de leitura. A suspensão causada pela narrativa polimórfica impede a fruição e, a menos que o leitor dê um sentido para a quantidade de discursos presentes, é impossível que a leitura resulte em uma compreensão satisfatória e prazerosa.

Além das lacunas, que estabelecem a ligação entre os segmentos textuais, Iser (1999, p. 29) também define as negações, que anulam o que parece familiar ao leitor e o fazem repensar seu repertório, o que normalmente lhe causa certo desconforto na leitura, mas que "estimulam o leitor a suprir o que falta". Levanto então, a partir de uma pesquisa em leituras de outros níveis, as conexões necessárias que o leitor deve fazer para dar sentido à estrutura narrativa fragmentada e também à falta de explicação e de referentes empíricos para os elementos reconhecíveis da narrativa, como a Noiva e a Viagem, e até mesmo o próprio Cara-deBronze.

O nosso segundo leitor completa a primeira lacuna entre ele e o texto e, mesmo sendo incapaz de completar todas as outras inferências intratextuais, consegue tecer uma linha interpretativa, partindo da assertiva de que o conto se trata de uma narrativa mise en abyme, sentindo-se motivado a reler

${ }^{5}$ Termos grifados com maiúscula no texto de Rosa. 
o texto a fim de dar-lhe um sentido global, que contemple tanto sua forma quanto seu significado final. A leitura metaficcional é, portanto, a primeira alternativa que encontra em seu repertório teórico para dar sentido à estrutura e ligá-la a uma possível compreensão do tema pretendido pelo texto. Apesar de perceber que o tema da narrativa é o da busca das Palavras, que a viagem de Grivo tem como objetivo encontrar histórias para contar ao Velho, e os Nomes das Coisas que ele próprio, impossibilitado por sua doença não poderia ver, as referências a Goethe, a Dante e outras tantas ficam mal resolvidas, necessitando de uma pesquisa mais profunda sobre mitos e personagens clássicos. Desse modo, a Noiva também perde seu sentido, e é mais uma nuance da narrativa não resolvida por este leitor.

Os elementos líricos, as notas e citações e o roteiro cinematográfico são vistos como partes integrantes do texto, e de igual importância para sua compreensão quanto ao tema central. Mas, apesar de seus esforços, o leitor de segundo nível é fadado a uma compreensão apenas parcial, pois dificilmente consegue ligar todos esses elementos de maneira satisfatória e completa. Sua falta de familiaridade com o tipo de literatura que Rosa inaugura impede que ele siga independente em sua análise sem recorrer a outros teóricos, pois na mesma medida em que o texto exige uma compreensão dos elementos intratextuais, ele também demanda um grande esforço mental e referencial para relacioná-los com os extratextuais que porventura o leitor também domine.

As leituras apresentadas a seguir confirmam as barreiras que existem, e que di- ficultam o trabalho do leitor para ligar todas as suas partes satisfatoriamente, pois contemplam um ou outro aspecto do texto que, dependendo do ângulo a partir do qual são vistos podem ficar ocultos ou não, pois o conto é uma constante negação no que diz respeito às formas de narrar uma história. Estes leitores têm um repertório que permite que os elementos narrativos em suspensão sejam postos de tal forma em ordem que oferecem luz aos leitores menos experientes, sinalizando um caminho que possam tomar em suas leituras, pois "as deformações sinalizam algo além delas mesmas. Cabe ao leitor imaginar "as causas ocultas das deformidades aparentes" (ISER, 1999, p. 32) ativando sua enciclopédia para completar as lacunas e resolver as negações, pois a interpretação de "Cara-de-Bronze" depende tanto dos elementos intratextuais quanto da atividade ideacional do leitor. "Deste modo, a seqüência de idéias que se forma na mente do leitor com base na estruturação prefigurada pelo texto, isto é, nas suas operações estruturantes previamente determinadas, é a maneira pela qual o texto é traduzido na imaginação do leitor." (ISER, 1999, p. 30)

Baseados nesta estrutura oscilante, os próximos estudos nos mostram como um texto que não se finda em seu enredo pode suscitar mais interpretações interessantes que outras simples e lineares, que vão de encontro com as expectativas dos leitores gastronômicos. Também nos revelam qual a postura destes leitores diante deste conto, pois dão mais valor a certas abordagens e elementos, e suavizam a importância de outros. 
Nosso terceiro leitor, Benedito Nunes, é o autor de um dos mais famosos ensaios sobre "Cara-de-Bronze", que faz parte da coletânea $O$ Dorso do Tigre, organizada entre os anos de 1962 e 1967. O texto oferece um extrato de leitura que trabalha com os elementos mitológicos presentes e com temas recorrentes em Rosa, como a viagem e o maravilhoso, em uma leitura análoga aos romances de cavalaria. De acordo com $\mathrm{Nu}-$ nes, o dono da fazenda de Urubuquaquá, o Cara-de-Bronze, aparece como a figura do Rei Arthur, doente e velho como ele, e Grivo figura como o cavaleiro Galaaz, jovem forte e capaz, que sai em missão a serviço do Rei. Segundo Nunes, o tema da viagem confere ao conto seu aspecto polimórfico, sua estrutura lírica e os efeitos da mimese, que parte do cotidiano dos vaqueiros para atingir os domínios do maravilhoso. Ele afirma que os temas gerais a toda a obra de Rosa - o motivo da viagem, a estrutura polimórfica e o horizonte mítico-lendário - que aparecem neste conto são unidos, e veiculam a concepção de mundo do autor.

A viagem, portanto, configura-se como "a travessia por entre as Coisas; a Palavra é a vida para o Velho e a missão de Grivo retraça o surto originário da linguagem, recupera a potencialidade criadora do Verbo" (NUNES, 1962 e 1967, p. 184), o que prova que a narrativa tange temas universais. A Viagem configura-se também como uma narrativa dentro da outra, uma vez que encontramos a estória da Demanda do Santo Graal, e a narrativa da própria narrativa. Grivo é o menino mítico, comum a outros textos rosianos, que promove a ligação entre o maravilhoso (Segisberto
Jéia) e o comum (os vaqueiros), provocando o desabrochar do contexto realista do texto. Nesta perspectiva, o quarto do velho é como a corte do Rei Arthur e Urubuquaquá é este contexto realista, por ser um ambiente social específico. A estrutura polimórfica, com seus cortes, trabalha para unir os dois mundos: a esfera mito-poética e a realidade concreta. Mais ainda, o autor afirma que as notas e citações podem auxiliar nesta leitura, mas não interferem no texto.

A partir do artigo de Nunes, verificamos que o texto de Rosa não permite uma anarquia interpretativa por parte do leitor, mas sim um leitor de talento, que recorra ao seu cabedal de experiências e conhecimento para completar as lacunas e dar sequência à narrativa e à estrutura textual que, mesmo recaindo sobre si mesma, atinge temas universais. $O$ vaqueiro mais capaz é a figura do herói recorrente no imaginário coletivo, ao qual Rosa provavelmente recorreu, e cuja menção Nunes não deixou de fazer. Atingindo a esfera mitológica, vários outros temas como a viagem, a fidelidade e o mistério sobre Segisberto Jéia são retomados pelo crítico, o que nos permite concluir que a experiência do leitor coincidiu com a sofisticação do texto. Seus vazios modificam e estimulam o leitor, o que culmina na satisfação da resolução do enigma proposto pelo texto.

Já Rui Mourão (1994), também um aclamado estudioso de Rosa, faz uma leitura que parte de uma ótica metafísi$\mathrm{ca}$ em seu ensaio "Processo da linguagem, processo do homem", de 1994. Numa mesma perspectiva de que a narrativa age e reage sobre si mesma, ele afirma que todos os 
elementos sofrem um antropomorfização, desde as árvores até as plantas e os animais, em menor número. Grivo vai buscar e encontra a Verdade, que não é saber de tudo, mas descobrir que não se pode encontrar a verdade para todas as coisas. O "Cara-de-Bronze" é, portanto, simbólico da vida em si, e a relação entre o Grivo e Segisberto Jéia é a do mestre e do discípulo, que aprende com a viagem a Verdade maior sobre todas as coisas. Esta leitura mostra-se, portanto, tão elucidativa quanto a anterior, além de ser comprovada a partir de elementos objetivos do texto. A diferença de interpretação ocorre porque nos deparamos com a enciclopédia de outra pessoa, e a sua subjetividade põe os elementos sob outra luz.

Mais dois ensaios permitem que vejamos o texto de Rosa de ângulos bastante adversos às anteriores. De uma base psicanalítica, Cleuza R. P. Passos (2001) afirma que a linguagem é usada para falar do real, mas que a impossibilidade em retratá-lo a obriga a usar de outras roupagens para fazê-lo. A literatura, então, esmera-se para ser sua representação referida, mesmo com a barreira lingüística que lhe é imposta. $O$ fictício, segundo sua ótica, cumpre a tarefa de dar forma e de sustentar a existência dessa realidade, que nada mais é que fingimento, ficção. É uma realidade específica, idiossincrática ao real empírico, e contamina a função da realidade referencial. Este fingimento está presente tanto na literatura quanto na psicanálise, pois "a realidade psíquica pode aflorar com peso semelhante à referencial” (2001, p. 22). Sob esta ótica, encontramos em "Cara-de-Bronze tanto a descrição dos Campos Gerais quanto os complexos desejos e destinos singulares, ambiente no qual a verdade e o logro encontram espaço, assim como a realidade e o maravilhoso, o moderno e o arcaico. $O$ texto metaficcional o torna uma força que se calca no desvendar da natureza dos Gerais e da psique de alguns personagens, mas que ao mesmo tempo quebra a narrativa em uma mistura de formas literárias, de temas, de tempos verbais e foco narrativo, dando ao conto uma forma polivalente, que aceita várias interpretações. O desenredo - típico de Rosa, segundo a autora - pode ser exemplificado no fato de a Noiva não ser de carne e osso, e sim de Palavras; na viagem do Grivo, na íntegra, ser contada somente ao Velho, deixando o leitor e os outros vaqueiros em suspensão.

O cerne do texto, que é a busca das Palavras e o fato de a narrativa falar de si mesma e do próprio fazer literário, continua em vigor também nesse ensaio. A mescla de formas, segundo a autora, dá conta de um mundo complexo e real dos Gerais, da singularidade de cada personagem, além de também falar da própria narrativa que, por sua vez, lembra tanto o ciclo de temas novelísticos de Rosa, quanto de seu fazer literário, tudo condensado em um mesmo conto.

O próximo texto, de Heitor Martins (1983), traz análise a partir do ensaio de Benedito Nunes, tomando-a como base para então seguir em uma direção completamente oposta. "Em Urubuquaquá, em Colônia”, de 1983, localizado em um meio-caminho cronológico entre os textos de Rui Mourão, Benedito Nunes, e 
a mais contemporânea Cleusa Passos, é interessante para analisarmos as variações interpretativas em momentos históricos diferentes. A atenção dispensada a Grivo e sua viagem nos artigos anteriores a este é deslocada para a personagem-título, pois o Cara-de-Bronze estampado na abertura indica claramente o caminho a ser traçado na leitura. Podemos desde já frisar como Martins enfatiza que as delimitações da leitura são dadas pelo próprio texto, e que o caminho a ser feito pelo leitor não é necessariamente uma opção, mas já previsto pelas estratégias enunciativas. Com o Velho em mira, Martins preocupase em comprovar o mito de Édipo, uma vez que o personagem-título é suspeito de ter matado seu próprio pai por um incidente e sua mãe nunca é mencionada. Além disso, há elementos do teatro grego em toda narrativa $^{6}$, e a moldura lírica do cantador somada a todos os elementos do arquétipo presentes - o assassinato do pai, a doença, etc. - conferem autenticidade à leitura simbólica de Cara-de-Bronze como Édipo. O ensaísta ainda defende que com a estrutura polimórfica somada a elementos teatrais o conto assume a forma de uma peça teatral, dando ainda mais vazão à antiga querela genérica sobre este texto.

Enfim, excetuando-se a primeira, todas as leituras recaem sobre o mesmo amontoado de palavras e encontram um problema

\footnotetext{
${ }^{6}$ Exemplos destes elementos são os vaqueiros como coro, as chegadas e partidas de diversos personagens, pois a maioria dos vaqueiros não trabalha no Urubuquaquá, e a presença do velho vaqueiro Tadeu, prestando os devidos esclarecimentos, como um intermediário entre a platéia e a história.
}

semelhante: a solução do significado de sua estrutura dentro da esfera interpretativa do conto, a descoberta do motivo da viagem do Grivo e sua verdadeira missão, e o mistério que envolve o Cara-de-Bronze. O que foge à compreensão da primeira leitora foge também dos outros leitores e ensaístas mas, diferentemente dela, cada leitor especializado encontra a solução para estes problemas à sua maneira, recorrendo a seu repertório, ou seja, às suas técnicas e conhecimento pessoais para resolver o enigma do conto.

\section{Considerações finais}

Apesar do número limitado de leituras que este artigo analisou, foi possível constatar que o texto de Rosa não é hermeticamente fechado, mas construído de tal forma que quando manejado e especulado dentro de seus limites referenciais oferece luz a leituras variadas, que elucidam outros ângulos talvez não contemplados em outras anteriores. Ele é certamente provido de uma univocidade preestabelecida da qual nenhum leitor pode fugir. Entregar-se a ele é também entregar-se à sua forma e ao como ele foi construído, uma vez que esses elementos objetivos são os seus instrumentos para que seu significado último seja estabelecido.

Desse modo, as diferentes interpretações não se excluem, mas unemse como auxiliadoras para dar conta da riqueza estrutural do conto. Um texto como o de Rosa permite várias leituras em vários momentos históricos, e elas revelamse todas satisfatórias e complementares, diferentemente de uma literatura gastronômica, que permite apenas uma 
leitura que se esgota fechada em seu enredo por não possuir elementos implícitos que possam ser investigados e vistos a partir de diversos ângulos. Eco (1989, p. 100) afirma que "todo texto aspira proporcionar prazer em sua leitura adequada.". O leitor de Rosa, portanto, poderá encontrar prazer em aventurar-se em resolver os enigmas da narrativa, para então encontrar a grande satisfação em superar seus desafios. Ele deve apresentar-se habilidoso para vencêlos, pois a narrativa é elaborada e dificulta sua compreensão. Os leitores somente preocupados com o enredo não encontram a razão de ser de um texto que brinca com o fazer literário, que por sua vez faz parte de seu jogo. A atenção ao fazer narrativo promove leituras múltiplas, pois entramos no jogo do autor e nos tornamos seu leitormodelo, capaz de lançar-se ao desafio de resolver os quebra-cabeças propostos.

Segundo Eco (1989, p. 100) todo escritor, mesmo o mais experimentalista "quando sabia que ia contra o horizonte de expectativas do seu próprio leitor comum e atual, aspirava a formar um futuro leitor particular, capaz de entendê-lo e de saboreá-lo." Os leitores-modelo que Rosa já formou para "Cara-de-Bronze" constituem um público restrito, habilidoso e especializado, pois o prazer que o leitor de Rosa encontra depende, e muito, de suas habilidades para trabalhar com o texto. É um trabalho envolvente e árduo, no qual nem o texto pode ignorar o leitor, nem este pode ignorar suas estratégias narrativas.

Finalmente, mesmo inaugurando uma literatura altamente experimental com
"Cara-de-Bronze", creio que Rosa também desejava ser lido e acreditava na existência de um leitor que pudesse saborear sua compreensão e que desejasse aventurar-se na difícil tarefa de resolver os seus enigmas. Este conto é, ainda hoje, compreendido somente por um grupo singular de leitores de níveis avançados e, mesmo neste caso, cada leitor leva a obra para seu campo de conhecimento e chega a uma etapa de sua compreensão, dependendo muito da habilidade e do desejo do fruidor em aventurar-se pelos sertões de Rosa. Como ele mesmo afirma, utilizando seu narrador como porta-voz:

Não. Há aqui uma pausa. Eu sei que esta narração é muito, muito ruim para se contar e se ouvir, dificultosa; difícil: como burro no arenoso. Alguns dela vão não gostar, quereriam chegar depressa a um final. Mas - também a gente vive sempre somente é espreitando e querendo que chegue o termo da morte? Os que saem logo por um fim, nunca chegam ao Riacho do Vento. (ROSA, 1976, p. 96)

\section{REFERÊNCIAS}

COMPagnoN, A. O Demônio da Teoria: literatura e senso comum. Trad. C.P.B. Mourão e C.F. Santiago. Belo Horizonte: Editora UFMG, 1999.

ECO, U. O Texto, O Prazer, O Consumo. In: Sobre os espelhos e outros ensaios. 2.ed. Trad. Beatriz Borges. Rio de Janeiro: Nova Fronteira, 1989.

\section{Seis Passeios Pelos Bosques da}

Ficção. São Paulo: Companhia das Letras. 1994. 
Obra Aberta: forma e determinação nas poéticas contemporâneas. Trad. Pérola de Carvalho. São Paulo: Perspectiva, 1971. Pg. 41 -65 .

ISER, W. Teoria da Recepção: reação a uma circunstância histórica. In: $\mathbf{O}$ ato $\mathbf{d a}$ leitura: uma teoria do efeito estético. Trad. J. Kretschmer. São Paulo: Editora 34, 1999. 2v.

JOUVE, V. A Leitura. São Paulo: Ed. Unesp. 2002.

MARTINS, H. No Urubuquaquá, em colônia. In: Do Barroco a Guimarães Rosa. Vol.12. Belo Horizonte: Itatiaia LTDA, 1983.

MOURÃO, R. Processo da linguagem, processo do homem. In: ROSA, João Guimarães. Ficção Completa. Vol. I. Rio de Janeiro: Nova Aguilar S.A., 1994.

NUNES, B. A Viagem do Grivo. In: O Dorso do Tigre. São Paulo: Perspectiva S.A. Ensaios publicados no Estado de São Paulo e Minas Gerais entre 1962 e 1967.

PASSOS, C. R. P. O contar desmanchando.... artifícios de Rosa. In: Outras Margens. Estudos da obra de Guimarães Rosa. Org.: ALVES, M. T., DUARTE, L. P., Belo Horizonte: Autêntica. 2001.

ROSA, J. G.. Cara-de-Bronze. In: No Urubuquaquá, No Pinhém. Rio de Janeiro: Livraria José Olympio Editora, 1976.

Recebido para publicação em 02 de Jun. 2014. Aceito para publicação em 22 de Ago. 2014. 